that the dangers of delayed diagnosis and treatment of this infection are not fully appreciated.

A delay in diagnosing falciparum malaria is not uncommon because the early stages of the infection may mimic many trivial diseases. Thus malaria must be suspected in any patient with fever of unknown or doubtful origin who has ever been to a subtropical or tropical area. Information on the patient's history is of paramount importance in this respeot- "Where have you been and when?" The diagnosis of malaria can be clinched by a laboratory report on a blood film, but it also requires sound clinical judgement. An outline of the main aspects of the epidemiology, prevention, diagnosis, and therapy of malaria has been given in this journal, ${ }^{9}$ and a comprehensive and handy publication of the Ross Institute of Tropical Hygiene provides much sound advice on the subject. ${ }^{10}$

Any person wishing to travel to a malarious country may be protected by a preventive drug regimen. Normally he should take prophylactic (proguanil or pyrimethamine) or suppressive drugs (chloroquine or amodiaquine). The difference between the two groups lies in their action on some specific stages of malaria parasites, but Dr. Rowland gives reasons for preferring proguanil or pyrimethamine to the suppressive drugs. These drugs should be taken at the appropriate dosage and frequency during the exposure to the infection and for four weeks after return to the nonmalarious area. Other methods of individual protection from mosquito bites, such as long sleeves and trousers after dark and a mosquito bed-net, if necessary, must not be neglected.

In some parts of the world malaria parasites have developed various degrees of resistance to common antimalarials. Resistance to proguanil and pyrimethamine may result in occasional "breakthroughs" of malaria against their prophylactic action. Moreover, during the past few years observations of resistance of $P$. falciparum to 4-aminoquinolines (chloroquine and amodiaquine) have been confirmed in Burma, Cambodia, Laos, Malaysia, Phillippines, Vietnam, parts of Brazil, Colombia, and eleswhere. It seems that this resistance is slowly spreading in eastern Asia, but there is no evidence of chloroquine resistance in Africa. Resistance to 4-aminoquinolines is causing great concern as these compounds (together with quinine) are our most valuable drugs for the treatment of acute malaria. The discovery of the potentiation between sulphones or sulphonamides on the one hand and pyrimethamine or trimethoprim on the other has given us some new and valuable drug combinations for treatment of malaria resistant to other synthetic compounds. ${ }^{11}$ Lately two antibiotics (lincomycin and tetracycline) have shown some promise. Much research on chemotherapy of malaria is in progress, particularly in the U.S.A., and it is likely that some new antimalarials will emerge from the large number of compounds now undergoing laboratory tests and field trials.

1 Maegraith, B. G., Exotic Disease in Practice. London, Heinemann, 1965. 2 British Medical fournal, 1971, 2, 1.

3 Public Health Laboratory Service, 1971 Year Book including Annual Report for 1970. London, 1971.

4 Dorolle, P., British Medical fournal, 1968, 4, 789. World Health Org

- Department of Health and Social Security, Communicable Diseases Contracted Outside Great Britain, 1968 (new edition in press).

7 Ross Institute of Tropical Hygiene, Preservation of Personal Health in Warm Climates, 7th edn. London, 1971 .

8 Shute, P. G., and Maryon, M., British Medical fournal, 1969, 2, 781.

9 Bruce-Chwatt, L. J., Draper, C. C., and Peters, W., British Medical Fournal, 1971, 2, 91 .

10 Ross Institute Information and Advisory Service, Antimalarial Drugs. (Bulletin No. 2) London, 1972.

11 Peters, W. Chemotherapy and Drug Resistance in Malaria. New York, Academic Press, 1970.

\section{Mercury in the Environment}

In the past few years several careful studies in different parts of the world have drawn attention to the exposure of the human population to mercury in its different chemical forms. They were briefly reviewed in these columns ${ }^{1}$ after the discovery that some popular edible fish might contain up to 0.5 p.p.m. methyl mercury which they had picked up from their natural environment. Could fish containing such amounts of methyl mercury present a health hazard to their human consumer? The question was raised by the discovery that in some situations waste mercury, deposited in what was believed to be the biologically insignificant form of the insoluble sulphide, could be converted to water-soluble toxic methyl mercury derivatives by micro-organisms. It is not therefore surprising in view of other public statements ${ }^{2}$ and reviews ${ }^{3}$ that the Expert Committee on Food Additives convened by the World Health Organization and the Food and Agriculture Organization should have set itself the task of proposing an acceptable daily intake of the three toxic chemicals lead, cadmium, and mercury, and will issue a report.

Mercury in its various chemical forms presents different hazards to man. It is generally accepted that the lower alkyl mercury derivatives-methyl or ethyl mercury salts-have a unique destructive effect on the nervous system of higher animals and man. This has been found because people have been accidentally or occupationally exposed to concentrations of these organo-mercury compounds generated directly by man's activities. There is no indication that mercury of natural origin and dispersion is converted to methyl mercury in dangerous concentrations, but mercury released by human activities in different forms can be so converted in amounts that have killed or crippled thousands of people. It is right that the hazards presented by mercury in our human environment should arouse concern, but equally they must be seen in perspective. While the deaths of 2,000 people in Iran recently from the effects of an earthquake were given publicity, little attended the deaths of several hundred and the crippling of many thousands of Iraqis to which reference was briefly made in our columns ${ }^{4}$ in an appeal for help. The deaths and disability affecting the Iraqis were due to a toxic substance made by man and introduced into that country as a seed dressing aimed at improving th eyield from wheat or barley. Unfortunately, the seed grain was dressed with a mercurial compound known to produce irreversible injury in man. It was distributed after the sowing season ${ }^{5}$ and so was eaten by a people used to eating their seed grain. 67 The current concern with environmental hazards is finding expression at a U.N. conference in Stockholm. But will anything be done to control the manufacture of certain fungicides and insecticides that have already killed and crippled thousands of people?

The human wreckage from the distribution of methyl mercury is widespread in parts of Asia. The International Red Cross did a fine job in organizing the rehabilitation of 10,000 people paralysed by triorthocresyl phosphate sold as edible cooking oil in Morocco in 1959,8 but the devastation in Iraq is probably less amenable to therapy and rehabilitation. There is a danger that hypothetical hazards will attract study while little is done to prevent real hazards, for it is easier to form pious resolutions than to stop people doing dangerous things. But the manufacturers and distributors of substances known to be dangerous can be identified 
and their activities controlled-though probably only by the concerted action of medical men.

1 British Medical fournal, 1971, 1, 126.

2 Massachusetts Department of Public Health, New England fournal of Medicine, 1972, 286, 840

3 Joselow, M. M., Louria, D. B., and Browder, A. A., Annals of Internal Medicine, 1972, 76, 119 .

4 Damluji, S. K., and Tikriti, S., British Medical fournal, 1972, 1, 804.

- Daily Telegraph, 25 February 1972, p. 32.

- Al-Kassab, S., and Saigh, N., fournal of the Faculty of Medicine, Baghdad,

1962, 4, 118 .
Jalili, M. A., and Abbasi, A. H., British Fournal of Industrial Medicine, 1961, 18, 303.

${ }^{8}$ Albertini, A. V., Gross, D., and Zinn, W. M., Triaryl Phosphate Poisoning in Morocco 1959. Stuttgart, Georg Thieme.Verlag, 1968.

\section{Glucose Tolerance in Bed}

The effect of exercise in reducing glycosuria and blood sugar in diabetics was clearly demonstrated in the pre-insulin era by F. M. Allen. ${ }^{1}$ R. D. Lawrence ${ }^{2}$ added the observation that exercise potentiated the hypoglycaemic effect of insulin, information which should be, but unfortunately is not always, communicated to all diabetics when insulin therapy is begun. Recently D. M. Klachko and colleagues ${ }^{3}$ have used the technique of continuous blood-glucose monitoring to follow the effects of graded exercise on diabetics who require insulin and on non-diabetics. Moderate exercise-walking on a treadmill-had a more profound effect on blood glucose levels in the diabetics. The degree of fall seemed to depend on the level of blood glucose at the onset of exercise as well as the amount of exercise taken. Furthermore, in the diabetics there was no rebound rise of blood glucose after the exercise, a phenomenon observed in several studies of non-diabetics. ${ }^{3-5}$

In non-diabetics the effects of exercise on the blood glucose level are variable and depend on a number of factors. J. R. Sutton and colleagues ${ }^{6}$ found that vigorous exercise on a bicycle ergometer caused a rise in blood glucose in fit people but a fall, followed by a rise in the rest period, in the unfit. J. K. McKechnie and colleagues ${ }^{7}$ studied fit longdistance runners and noted an apparent effect of diet before the race. When the athletes were on a sugar-free diet, the blood glucose was lower at the end of the race than before it began, whereas when they were on an unrestricted sugar intake the blood glucose was higher at the end than at the start. F. Schwarz and colleagues ${ }^{8}$ studied normal and obese people performing bicycle ergometer exercise and noted that the blood glucose remained stable in all those of normal weight. However, in 4 out of 10 obese people the blood glucose rose. It is probably significant that the obese people had much more difficulty in performing the exercise. That the kind of exercise and the element of competition or difficulty may also be important is further supported by the observation of considerable rises in blood glucose levels in squash rackets and badminton players during play. 9

There is little evidence that, under ordinary circumstances, exercise affects glucose tolerance. P. Björntorp and colleagues ${ }^{10}$ studied ten obese patients who were subjected to fairly intensive physiological training over a period of eight weeks, resulting in increased maximal oxygen consumption and increased isometric muscle strength. Weight actually increased, primarily owing to an increase in body fat. Blood glucose levels in oral glucose tolerance tests performed before and after the training period were not significantly different. However, insulin levels were strikingly lower in the second test, suggesting that the physical training had somehow re- moved the insulin insensitivity associated with obesity. When physical activity is much diminished, however, glucose tolerance both intravenous ${ }^{11}$ and oral is impaired. This has recently been studied by $R$. L. Lipman and colleagues, ${ }^{12}$ who confirmed that bed rest impaired glucose tolerance and $\stackrel{\square}{T}$ showed that the impairment was associated with reduced $\frac{3}{8}$ peripheral uptake of glucose. Significant impairment of $\stackrel{\mathbb{Q}}{\complement}$

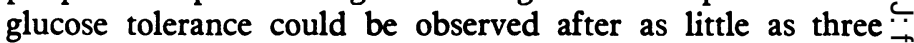
days' bed rest, so this factor must clearly be considered in $\overrightarrow{\vec{s}}$ the interpretation of glucose tolerance tests in the bedridden patient. Exercise in the supine position for only one hour a $\underline{\bar{O}}$ day diminished but did not completely abolish the glucose $\frac{\bar{\Phi}}{\vec{D}}$

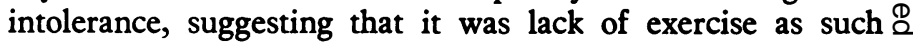
and not the effects of the prolonged supine position which had this effect. Exactly how physical exercise affects glucose $\vec{\circ}$ intolerance remains to be established, though $M$. S. Gold$\operatorname{stein}^{13}$ has found in animal experiments a humoral factor, $\vec{\omega}$ released from exercising muscle, which has a hypoglycaemic $\frac{D}{3}$ effect.

1 Allen, F. M., Stillman, E., and Fitz, R., Total Dietary Regulation in the Treatment of Diabetes. New York, Rockefeller Institute for Medical $\vec{A}$ Research, 1919.

2 Lawrence, R. D., British Medical fournal, 1926, 1, 648.

3 Klachko, D. M., Lie, T. H., Cunningham, E. J., Chase, G. R., and Burns, T. W., Diabetes, 1972, 21, 89. T. W., Diabetes, 1972, 21, 89.
1935, 111, 21 .

${ }^{5}$ Harris, P., et al., Quarterly fournal of Experimental Physiology, 1968, 53, 43.

- Sutton, J. R., Young, J. D., Lazarus, L., Hickie, J. B., and Maksvytis, J., Australian Annals of Medicine, 1969, 18, 84. J. B., and Maksvytis, J.,

${ }^{7}$ McKechnie, J. K., Reid, J. V., and Joubert, S. M., South African Medical Fournal, 1970, 44, 728. Schwarz, F., ter Haar, D. J.,
Metabolism, 1969, 18, 1013.

9 Green, L. F., and Jarrett, R. J., unpublished observations.

10 Björntorp, P., de Jounge, K., Sjöström, L., and Sullivan, L., Metabolism, $1970,19,631$.

${ }^{11}$ Lutwak, L., and Whedon, G. D., Clinical Research, 1959, 7, 143.

12 Lipman, R. L., et al., Diabetes, 1972, 21, 101.

3 Goldstein, M. S., in On the Nature and Treatment of Diabetes, p. 305, ed. B. S. Leibel and G. A. Wrenshall. Amsterdam, Excerpta Medica, 1965.

\section{Hunter Reports}

Mention management or administration to the average doctor and he tends to bristle. Perhaps this is because a 8 doctor is trained to make quick decisions - often on his own -and tedious bureaucratic procedures with seemingly dil- 0 atory concensus decisions are anathema to him. Administrators $N$ are needed, however; the Health Service employs $900,000 \stackrel{\square}{\square}$ people, making it one of the largest employers in the world, so that even when reorganized and integrated it will still $\tilde{N}$ be a complex structure. A constructive relationship between clinical medicine and administration is more probable if the 0 N.H.S. contains appropriately trained medically-qualified administrators at all levels-an important plank in the B.M.A.'s policy on N.H.S. reorganization.

Decisions in the N.H.S. cannot just be handed down from ${ }^{\circ}$ the boardroom via the management; most of those that really $\frac{O}{\mathbb{D}}$ matter are made night and day in surgeries, homes, and $\stackrel{\odot}{\mathbb{D}}$ wards. Fortunately, the recently published report on medical $\stackrel{\mathbb{}}{\circ}$ administration by the Hunter Working Party, ${ }^{1}$ summarized in the Supplement this week (p. 143), appreciates this situation. Its task of reviewing "the functions of medical administrators in the health services" and making recom- $\frac{\bar{\sigma}}{2}$ mendations about their training could not have been easy, however, when the working party had no clear idea of the form of the reorganized N.H.S. at area and district levels. This was being worked out simultaneously by a McKinsey- 